\title{
De Greimas a Jean-Claude Coquet. O discurso e seu sujeito
}

\author{
Ahmed Kharbouch' \\ https://orcid.org/0000-0001-6807-0564 \\ I - Universidade Mohamed Premier \\ Oujda, Marrocos
}

Resumo: A "semiótica discursiva" fundada por Greimas estipula, a partir do ponto de vista antropológico que é o seu, que o discurso é a manifestação dos "jogos de coerções semióticas" próprios ao espírito humano. A partir dessa semiótica se constituiu progressivamente uma abordagem do discurso que se inscrevendo numa perspectiva fenomenológica, interroga os modos de participação do "sujeito enunciador" no seu dizer e no seu fazer, antes de mostrar que a significação discursiva é polifônica e que ela faz ouvir tanto a voz do logos quanto aquela da physis.

Palavras-chave: coerções semióticas; discurso; enunciação; perspectiva antropológica; perspectiva fenomenológica.

Abstract: From Greimas to J.-Cl. Coquet: The Discourse and its Subject - Greimas's "discursive semiotics" stipulated, from an anthropological point of view, that discourses are only the manifestations of "semiotic constraints" at play at the level of the "human mind". On the basis of his semiotics, reexamined in a phenomenological perspective, a new approach to discourse was later on gradually constituted. It explores the modes of participation of the "subject of the enunciation" to his own sayings and doings and shows that discursive meaning is polyphonic and expresses the voice of the physis as well as that of the logos.

Keywords: semiotic constraints; discourse; enunciation; anthropological perspective; phenomenological perspective.

\section{O jogo das coerções semióticas}

Enquanto a semiótica é comumente definida como "o estudo dos signos" ou, no melhor dos casos, como o reconhecimento e análise de sistemas de signos ou de significação, Greimas a concebe antes de tudo como uma semiótica discursiva' (GREIMAS,

1 Segundo Landowski, as denominações "semiótica discursiva", "semiótica estrutural" e "semiótica greimasiana" são intercambiáveis. Elas retomam um mesmo posicionamento no que se refere ao sentido, a não ser confundido nem com a "semiologia positivista" nem com o "pós-estruturalismo desconstrucionista" (LANDOWSKI, 2004, p. 25). 
1977, pp. 227-229). Paralelamente a uma semiótica dedicada à construção de tipologias cada vez mais refinadas de signos e códigos, existe de fato um lugar, como Eco havia pertinentemente ressaltado, para uma "semiótica do discurso" que tem como objeto a organização dos enunciados e visa dar conta, entre outras coisas, do "uso estético" dos "signos" (ECO, 1988, pp. 29, 63, 197).

A respeito disso, Greimas não se satisfaz com generalidades. A semiótica constitui para ele um "campo do saber" claramente circunscrito, caracterizado por "uma coerência metodológica que ultrapassa a diversidade de objetos examinados". Ela se dá por objetivo a organização e a tipologia dos discursos, domínio de estudo excluído do campo da linguística, no qual as preocupações se limitam à sintaxe da frase, e, ao mesmo tempo, tornado "disponível pelo abandono dos métodos (...) da retórica e da poética clássicas" (GREIMAS, 1977). A semiótica discursiva não é, portanto, a linguística. Mas, mesmo que ela esteja voltada aos mesmos tipos de objetos empíricos que a poética, a retórica ou ainda a estilística, a saber, o discurso, ela não pode ser confundida com elas. Ela se caracteriza, com efeito, por duas opções fundadoras que recordam as escolhas feitas por Saussure para circunscrever o objeto e o ponto de vista da linguística entre as outras disciplinas tendo como objeto a linguagem (SAUSSURE, 1980, pp. 20-35): de uma parte, precisamente, a escolha do "discurso", não somente como realidade empírica, mas, sobretudo, enquanto objeto a construir; de outra parte a escolha de um ângulo de aproximação específico: o ponto de vista semântico. O discurso não é mais então considerado nem como o lugar de uma simples comunicação argumentativa (conforme a perspectiva retórica), nem como a manifestação de um "estilo" individual (segundo a perspectiva estilística), nem tampouco como uma "composição" que responderia positiva ou negativamente às normas de um "gênero" socialmente codificado (segundo a perspectiva da poética), mas como um conjunto significante (COQUET, 1982, p. 34).

Antes de explicitar esta determinação, notemos que o termo "discurso" não é de uso fácil para quem se interessa pela análise da linguagem. Sobre este ponto, todo mundo, sem dúvida, estará de acordo com Michel Arrivé e seus amigos gramáticos: esse vocábulo conhece empregos tão variados e admite delimitações tão fluidas que "parece que não há palavra mais polissêmica no campo da linguística" (ARRIVÉ; GADET; GALMICH, 1986, p. 233). Antoine Culioli justifica seu abandono pelo caráter confuso e pouco inteligível da noção que ele recobre (CULIOLI; NORMAND, 2005, pp. 142-143). No entanto, de outro lado, o recurso à dimensão discursiva oferece ao linguista vantagens notáveis. Além do fato de que só ele permite não se confinar na dimensão frástica, ele apresenta virtudes não meramente explicativas (COQUET, 1997, p. 38; 1982, pp. 11-12)², mas também de ordem

2 O discurso "tem valor explicativo" na medida em que diante "dos fenômenos morfológicos ou sintáxicos", objeto empírico habitual do linguista, é vantajoso, explica J.-Cl. Coquet, de coloca-los na dimensão discursiva para melhor compreendê-los (La quête du sens. Le langage en question, Paris, PUF, 1997, p. 38). Para isso, o analista deve partir não "dos enunciados isolados" mas de um discurso "que já produziu o conjunto dos enunciados submetidos ao exame (...). Cabe ao próprio discurso atuar como revelador: tal enunciado está aqui, tal outro não está aqui". (J.-Cl. Coquet, "L’implicite de I'énonciation", Langages, 70, 1982, pp. 11-12). 
"econômica" na medida em que funciona como uma "navalha de Occam". Em particular, frente à pretendida ambiguidade de certas frases, a problemática discursiva dispensa o pesquisador de jogos gratuitos aos quais os linguistas gerativistas e os semanticistas cognitivistas são afeiçoados. Com efeito, o discurso constitui por natureza um contexto desambiguizante para os enunciados que contém, e ele mesmo se insere sempre em uma situação sociocultural determinada que o define em relação aos outros discursos que ele encontra em seu caminho. O semioticista pode então parar de se interrogar sobre a significação problemática de expressões isoladas e voltar toda sua atenção sobre o "nível integrador" que é o discurso (COQUET, 1986, p. IV).

Em todo caso, para Greimas, a caracterização do discurso como constituindo um conjunto significante é suficiente por sua inteligibilidade e, por conseguinte, também para fazê-lo um objeto próprio da semiótica. Mantendo-se fiel à herança saussuriana, essa determinação o conduzirá a praticar, à semelhança de Hjelmslev, uma análise imanente. Para entender essa posição, é necessário se recordar que a noção de "signo" tal qual Saussure a emprega é bastante distante daquela que foi legada pela tradição filosófica (aliquid stat pro aliquo) e retomada como tal por Peirce (1978, p. 121) (o signo entendido como qualquer coisa no lugar de qualquer outra coisa por qualquer um). O signo saussuriano não é um elemento $A$ que serve, ao intérprete, como substituto a um elemento B. Pois, como Saussure mesmo sublinhou, é o "significante" que seria neste caso o signo do "significado". Muito além, se Saussure (2002, pp. 104-105) (cuja notável reserva terminológica é bem conhecida) utiliza a palavra "signo" para designar a relação de significação entre o "significante" e o "significado", é somente porque não encontrou algo melhor para a substituir: "a língua usual não sugere nenhuma outra" (SAUSSURE, 1980, pp. 99-100)3.

Como unidade semiológica, o signo é caracterizado antes de tudo por sua autonomia em relação à "realidade". Quando Saussure define a língua como "um sistema de signos que exprimem as ideias" (SAUSSURE, 2002, p. 32), ele toma a palavra "signo" em sua acepção tradicional de representação de qualquer coisa: o signo linguístico representa a ideia. Não ocorre o mesmo quando ele estabelece a distinção entre significante e significado, pois a relação de reenvio ou de substituição entre as duas entidades se encontra então situada no interior do signo, totalidade semântica autônoma que Saussure figura didaticamente não pela tradicional flecha de reenvio, mas sob a forma de uma elipse que indica claramente que não se trata de duas coisas heterogêneas colocadas em relação pela representação (o signo e seu objeto) mas de um "conjunto significante" autônomo que se apresenta diante do intérprete como um "todo de significação" (SAUSSURE, 2002, p. 159).

A escolha da expressão "conjunto significante" para designar "a reunião do significante e do significado" denota, portanto, da parte de Greimas (1979, p. 128), uma leitura penetrante do Curso, da qual poucos de seus contemporâneos foram capazes

3 Em suas notas manuscritas, Saussure propõe utilizar o termo "sema" no lugar de "signo". (Ecrits de linguistique générale, Paris, Gallimard, 2002, pp.104-105). 
(CHEVALIER; ENCREVÉ, 2006, p. 61) (ULLMANN, 1952, pp. 19-24)4. No mais, Greimas introduz uma concepção "gerativa" do conjunto significante que é o discurso substituindo, de certa maneira, a barreira que separa o significado do significante na elipse saussuriana por um "percurso" que vai do plano do conteúdo em direção ao plano da expressão. O discurso se apresenta assim como uma totalidade significante autônoma autorizando uma análise imanente. O objeto do semioticista, nessas condições, é o de reconstruir, por simulação, o percurso que vai do plano do conteúdo imanente, já concebido pelos estóicos como "incorporal" (ECO, 1988, p. 39), à sua "encarnação", poder-se-ia dizer, no plano de expressão como manifestação, e fazer aparecer dessa maneira "os jogos das coerções semióticas" (GREIMAS, 1970, p. 135) entre as quais cada discurso particular estabelece um caminho que o conduz de um plano ao outro.

Façamos aqui uma pausa para notar que o fato de redefinir a problemática da significação como uma problemática do discurso é uma escolha metodológica judiciosa da parte de Greimas, mesmo que certos semioticistas pensem que a semiótica deva também integrar as "práticas vividas" e as "presenças humanas em ação" (engajadas nas "práticas"), em outras palavras, não somente o discurso sobre as "coisas", mas as "coisas" mesmas (LANDOWSKI, 2004, pp. 15-16; 26-29). A questão metodológica é ampla: quais dados reter para estudar, por exemplo, a significação da ocupação dos locais de uma empresa pelos grevistas? Essa generalização do objeto da semiótica é pressentida por Greimas e Courtés quando afirmam que "pode-se identificar o conceito de discurso com aquele de processo semiótico", e que, nesse caso, aquilo a que se denomina discurso "aparece como um conjunto de práticas discursivas: práticas linguísticas (comportamentos verbais) e não linguísticas (comportamentos somáticos significantes, manifestados pelas ordens sensoriais) (GREIMAS; COURTÉS, 1979, p. 102). É necessário dizer, entretanto, que aquilo que faz significar as "práticas vividas", são os discursos tidos sobre elas, dado que, no universo semântico, a linguagem constitui o interpretante último de todas as formações significantes que se encontram no espaço social global. É graças aos discursos que falam dela que uma prática é explicada e justificada, e que, de arbitrária, ela se torna motivada, o que é o propósito mesmo dos "mitos" que forja a ideologia social (BARTHES, 1957, pp. 211-213).

Assim, é com justa razão que a semiótica discursiva se funda sob a ideia de que a significação não reside diretamente nas coisas e nas práticas, mas nos discursos produzidos a seu respeito. Por exemplo, devemos empreender a análise das ações ou aquela dos relatos das ações? A resposta dada por Claude Brémond é convincente: "As 'ações em si mesmas' nos são tanto inacessíveis quanto as coisas em si da metafísica antiga". Por essa razão, "cabe a um certo tipo de discurso, chamado relato, de as colocar em uma forma que as torne inteligíveis. Em outras palavras, "uma teoria (semiótica) das ações 'em si-mesmas' é um não sentido. Só é concebível uma teoria das ações narradas" ou postas em discurso (BRÉMOND, 1973, p. 128).

4 Não obstante, segundo André Martinet, "um só tipo" teria "compreendido o curso, Hjelmslev". Para se convencer seria suficiente se reportar às teses de Stephen Ullmann sobre "a estrutura do signo linguístico". 
A adoção do discurso como objeto de análise é também um modo de limitar o número sempre importante das variáveis contextuais e impede, por consequência, a semiótica de se diluir naquilo que alguns chamam de "entorno pragmático". E mesmo se Greimas dá, às vezes, ao termo "discurso" uma extensão que o faz englobar tanto "os comportamentos verbais" quanto "os comportamentos somáticos significantes", na sua prática analítica, esses diferentes tipos de comportamento são apreendidos e modalizados no quadro de discursos particulares, sob a forma de "textos" (GREIMAS, 1987, p. 72). O seu slogan, "fora do texto não há salvação", pode ser compreendido como um convite ao semioticista: para não se reduzir à sociologia ou à estética, a semiótica deve se limitar à análise do discurso sobre as coisas. De fato, se concebermos que o sentido é apenas a possibilidade da interpretação (Hjelmslev, Eco), só o interpretante que é o discurso tido sobre o mundo como interpretado constitui o objeto do semioticista, pois é nele que se objetiva "o ato doador de sentido" (Husserl). Anterior a Benveniste, que considera que a língua é "o interpretante da sociedade", Greimas afirmava em seu texto fundador de 1956 que a língua enquanto "totalidade das mensagens trocadas" (ou seja, enquanto totalidade dos discursos produzidos pelos membros da sociedade) constitui o "significante" que recobre "um vasto significado, cuja extensão corresponderá, muito de perto, ao conceito de cultura" (BENVENISTE, 1956, p. 196).

Para a semiótica greimasiana, o problema essencial mantém-se, portanto, o da apreensão e da construção em termos explícitos da significação imanente do conjunto significante que é o discurso, objeto considerado, em seu parecer fenomenológico, como uma simples manifestação, no limite enganosa. Com efeito, “o nível dos signos (...) nos informa sobre a maneira como os sistemas semióticos se manifestam para nós, e não sobre seus modos de existência e de organização"; e, levando em conta que a estrutura é "uma rede de relações subjacentes à manifestação", o discurso não é mais que o lugar da manifestação de estruturas semânticas imanentes, de natureza transcultural, a que Greimas (1976, p. 19) denomina "semio-narrativas". Deste modo, o semioticista assume claramente, na análise do discurso, uma perspectiva antropológica.

De fato, se Greimas (1976, p. 19) concebe a organização subjacente a seu objeto empírico sob a forma de "estruturas elementares da significação" ou de "esquema narrativo", é na medida em que, como escreveu Lévi-Strauss "a estruturação possuiria (...) uma eficacidade intrínseca", eficacidade que também é acompanhada de um valor estético porque "a exigência de organização é uma necessidade comum à arte e à ciência". Em uma palavra, "a explicação científica [corresponde] sempre à descoberta de um 'arranjo'". Outra característica, não menos fundamental, do "projeto científico": a necessidade de dar a essas estruturas e a esses esquemas um estatuto de universalidade. Daí a dimensão antropológica do projeto: "as três mil sociedades etno-culturais que compõem a humanidade (...) possuem mutatis mutandis as mesmas formas narrativas". 
Sustentadas por "esquemas de pensamento generalizáveis", tais formas "não podem se explicar nem por influências, nem por modos de produção espontânea. Digamos que se trata de formas universais da humanidade" (GREIMAS, 1976, p. 19) (RUPRECHT, 1985, p. 284) $)^{5}$. Em outros termos, o agente que coloca em movimento o "percurso complexo" que conduz da imanência à manifestação (e que constitui por consequência o verdadeiro produtor do discurso) nada mais é que o "espírito humano" (GREIMAS, 1970, p. 135).

O ponto de partida adotado por Greimas explica que sua prática analítica seja estritamente ligada à abordagem analítica de Lévi-Strauss (2003, p. 57) a respeito dos mitos, abordagem esta que tem, como se sabe, por princípio a ideia de que "os mitos consistem em relatos, ou seja, em eventos narrados uns após os outros e que são imaginados para articular (...) sistemas de oposições entre imagens elas mesmas emprestadas do mundo sensível mas que adquirem uma significação lógica por elas estarem combinadas na forma de relações de oposições simples ou complexas". Ter-se-á reconhecido aqui os três níveis do "percurso gerativo" de Greimas: o nível lógico-semântico profundo ("sistemas de oposições", "significação lógica"), o nível narrativo de superfície, colocando em evidencia a organização algorítmica do discurso ("eventos narrados uns em seguida dos outros"), bem como o nível figurativo ("imagens emprestadas ao mundo sensível"). Objetar-se-á talvez que esse paralelismo entre a abordagem mitológica e a abordagem semiótica vale somente para o que Greimas (1979, pp. 5-7) chama os "discursos figurativos", aqueles que relatam eventos nos quais os agentes e os pacientes são entidades humanas ou antropomorfas. Mas se sabe, Greimas alargou sua concepção do discurso de tal maneira que possa englobar os "discursos cognitivos" de natureza didática ou argumentativa considerados como relatos de eventos não mais figurativos, mas de caráter abstrato, como os das ciências sociais [5]. Da mesma maneira, o discurso da paixão, ou "discurso passional", é considerado como a manifestação de um relato de eventos "patêmicos" ou de "processos-patêmicos". De qualquer forma, o conjunto desses tipos de discursos, por diversos que sejam, remete às mesmas estruturas semio-narrativas: são elas que, para Greimas (1979, pp. 189), produzem, da maneira mais geral, o "discurso sensato".

A atenção assim dada ao "relato" tem por corolário o fato de que a significação imanente ao discurso manifesto se reduz finalmente aos percursos lógicos entre termos conceituais. Com efeito, Greimas (1982, p. 164) sustenta a ideia que a significação discursiva não se situa no nível da figuração dos eventos, mas "no nível da estrutura do conteúdo, postulada sobre este plano discursivo". É assim que, por exemplo, o discurso do que é a receita da sopa ao pistou consiste, em última análise, em uma consecução ordenada, sob a forma de duas transformações relativas a três posições conceituais: /cru/ $\longrightarrow$ /não cru/ $\longrightarrow$ /cozido/. Pensamos que essa tomada de posição sobre a significação vem diretamente da análise mitológica praticada por Lévi-Strauss, que considera que

5 Entrevista de Hans-George Ruprecht com A.J. Greimas. RSSI, 1, 1984, p. 3. Segundo Jean Petitot, a semiótica de Greimas "visa ser uma antropologia estrutural do imaginário" (Les deux indicibles). 
"antes de haver uma consecução de palavras, o mito é uma consecução de conceitos" (GENETTE, 1995, p. 59).

Conforme a perspectiva antropológica adotada, o agente verdadeiro da produção do discurso, seja figurativo ou cognitivo, é portanto, para Greimas, uma espécie de instância impessoal e transcendente constituída por invariantes semióticas universais, a saber "o espírito humano". É, portanto, claro que a integração, no âmbito de tal dispositivo teórico, do tema da enunciação do discurso ou, formulação equivalente, da "instância do discurso" como atividade individual e singular, se torne problemática (BENVENISTE, 1966, p. 151; 1975, p. 80)6. Esse ponto certamente não escapa à Greimas (1966, p. 153). Em 1966, o autor identificou a enunciação àquilo que ele denomina o "parâmetro de subjetividade". Efetivamente, como ele menciona em Semântica Estrutural, "todo discurso pressupõe (...) uma situação não linguística de comunicação" que se encontra linguisticamente explicitada por um "certo número de categorias morfológicas". Contudo, ressalta ele, do ponto de vista semântico, esse plano não é em si mesmo pertinente, "a menos que a análise tenha escolhido esse parâmetro como objeto de descrição" (BENVENISTE, 1966, p. 153). É claro que esse "parâmetro", acompanhado de seus traços linguísticos, remete ao que Greimas (1979, p. 128) chamará mais tarde de "enunciação enunciada", a distinguir da "enunciação propriamente dita", logicamente pressuposta pelo enunciado (BENVENISTE, 1966, p. 128).

Em seguida, tratando daquilo que concerne "o discurso e seu sujeito", Greimas (1976, pp. 10-11) situará sua reflexão no quadro da oposição saussuriana entre "língua" e "fala" ou, de maneira mais ampla, em referência à Hjelmslev, entre "sistema" e "processo". Ele pode assim afirmar, ao se referir a Benveniste, que o discurso é "a língua enquanto assumida pelo homem que fala" e que a enunciação constitui "uma instância de mediação que garante a passagem de uma à outra das duas formas de existência" que são a língua virtual e o discurso realizado. Quanto ao "homem" que "assume" a língua para transformá-la em discurso, Greimas considera que tudo não passa de um "actante sintático" identificável com a noção, de uso corrente em linguística, de "sujeito falante". Trata-se, em outras palavras, de um puro "conceito gramatical: o homem que fala", e de maneira nenhuma de um "sujeito ontológico: o homem que fala". Colocar entre parênteses o plano ontológico constitui de fato para Greimas a indispensável garantia da "coerência da linguística (concebida como teoria geral da linguagem) em seu conjunto". O único "sujeito" que deve por conseguinte considerar a semiótica discursiva é o sujeito enquanto aquele que fala; no caso contrário, arriscar-se-ia a introduzir na análise um elemento "heterogêneo", a saber o "sujeito psicológico e transcendental".

6 Para Benveniste, "instância de discurso" e "enunciação" são designações equivalentes e ambas remetem a uma atividade de linguagem individual. A primeira, mais antiga, remete aos "atos discretos e cada vez únicos pelos quais a língua é atualizada em palavra por um locutor". A segunda, mais recente, recupera o "funcionamento da língua a partir de um ato individual de utilização". 
A partir de tais reflexões, parece-nos ouvir um eco longínquo das preocupações de Saussure (1980, p. 262) no momento em que, tentando situar a linguística em relação às "ciências naturais" e às "ciências históricas" no âmbito da "classificação das ciências", ele chegava à conclusão de que ela não pertencia nem a essas nem àquelas mas "a um compartimento de ciências que, se não existisse, deveria existir", e que ele denomina "semiologia" (SAUSSURE, 2002, p. 262). Esta ciência teria como objeto "aquilo que se produz quando o homem tenta significar seu pensamento mediante uma convenção necessária". Pode-se perguntar sobre a localização de tal processo: será que "o que se produz" tem lugar no espírito, o que reenviaria à psicologia? ou, antes, num plano intersubjetivo e mais amplamente social, campo da sociologia? A resposta implícita de Saussure consiste em neutralizar essa oposição ao afirmar que o semiológico está na intersecção de dois domínios: que é ao mesmo tempo social ("convenção necessária") e individual ("seu pensamento") (DUCROT, 1989, p. 166-167) . A mesma neutralização parece embasar a análise semiótica tal como concebida por Greimas, pois se trata essencialmente para ele de colocar em evidência aquilo que todo discurso individual deve às "coerções semióticas" universais. Mas o que nos parece o mais útil a destacar nesse ponto, é o fato de que Saussure atribui sem ambiguidade a origem da enunciação do discurso não ao pensamento, mas ao "homem" que a "significa", que a enuncia recorrendo ao único meio de que ele dispõe para comunicar com seus semelhantes: a "convenção necessária". Sausurre, como Greimas (1976, p. 130) em seguida, dá o nome de "sujeito falante" a esse homem-que-enuncia. Entretanto, enquanto Greimas o caracteriza restritivamente como "o lugar onde se encontra o conjunto de mecanismos de colocação da língua em discurso", seu predecessor o considerava enquanto "ser humano e ser social".

Nessas condições, não sendo mais que um mecanismo de conversão entre modos de existência, é por construção que o "sujeito do discurso" é, em Greimas, necessariamente imanente ao conjunto significante que se leva em consideração. Deste ponto de vista, ele é bastante próximo do "locutor-auditor ideal" de Chomsky, outro mecanismo que permite a passagem do virtual ao atualizado. Este autômato, para lhe dar um nome cartesiano próprio para agradar tanto Chomsky quanto Greimas, de fato não é mais que a instanciação linguageira de essa transcendência que é o "espírito humano". É ele o verdadeiro agente "da construção dos objetos culturais (literários, míticos, pictóricos, etc.)"; é ele que coloca em movimento o "percurso complexo" indo "da imanência à manifestação"; e é ele também que encontra "em seu caminho tanto as coerções que tem que aceitar, quanto as escolhas que Ihe é possível operar". Essas constatações explicam claramente, nos parece, o fato de que Greimas (1970, p. 135) tenha escolhido, para tratar do "discurso e seu sujeito", de se situar decididamente na linha da antropologia cultural. Para recapitular, o discurso aparece aqui como um "objeto autônomo", do qual

7 A noção de "pensamento" será explicitada por Charles Bally como "reação" subjetiva (tanto cognitiva e axiológica quanto afetiva) a uma "representação" objetiva. 
o semioticista pode e deve dar conta "independentemente das variáveis que constituem o emissor e o receptor" (GREIMAS, 1987, 311).

\section{A realidade das instâncias enunciantes}

São ao contrário essas "variáveis", concebidas de maneira generalizante como "instância de origem" e "instância de recepção", que vão constituir a pedra angular da teoria semiótica desenvolvida por Jean-Claude Coquet, colaborador crítico de Greimas. Esta teoria, dita "teoria das instâncias enunciantes", pode ser concebida em suas grandes linhas como um prolongamento crítico fecundo da semiótica discursiva greimasiana.

Entre essas duas concepções, a primeira diferença que deve ser enfatizada é que, de um lado, Greimas, ainda que se declare de bom grado próximo à fenomenologia (CHEVALIER; ENCREVÉ, 2006, p. 132), refere-se frequentemente à antropologia estrutural de Lévi-Strauss, enquanto, por outro lado, Benveniste, precursor reconhecido por Coquet (1997, pp. 73-79), adota como quadro efetivo de sua reflexão a fenomenologia da linguagem (embora seja surpreendente não encontrar nele nenhuma referência explícita a Merleau-Ponty, seu colega no Collège de France). Baseando-se sobre a perspectiva fenomenológica, torna-se de fato possível tematizar a ancoragem do "sujeito do discurso" no mundo cultural e natural, tanto como pessoa quanto como corpo próprio. No seu princípio mesmo, essa visada se opõe a uma perspectiva antropológica que reduz toda instância de discurso (tanto a produtora como a receptora) a um puro mecanismo e cujo carácter específico é de se situar desde o início fora de toda ancoragem na "realidade", na medida em que ela só tem em vista as "condições muito gerais do exercício do pensamento" (LÉVI-STRAUSS, 1990, p. 198).

Claro, nós não dispomos de nenhum critério definitivo para justificar a escolha de uma dessas perspectivas mais que da outra. Como sustenta Jean-Claude Coquet, em matéria de análise da linguagem, importa somente o "ganho de inteligibilidade". Todavia, se o "sujeito do discurso" é definido, à maneira saussuriana, como um "ser humano" e um "ser social", constata-se que para a perspectiva antropológica somente importa o "ser social", reduzido além disso à única dimensão funcional de um mecanismo de conversão da língua em discurso. Para retomar uma expressão conhecida, esse sujeito do discurso é entendido como um "homem unidimensional" na medida em que, entre as duas dimensões que determinam o que Coquet chama "ambivalência da linguagem", a saber a physis (o mundo sensível e o universo do corpo próprio) e o logos (o mundo inteligível e o universo do julgamento), apenas a segunda é retida. Toda referência à physis como dimensão fundadora é, portanto, excluída.

De qualquer forma, a perspectiva fenomenológica é do mais alto interesse para a semiótica do discurso. Concordamos com Umberto Eco (1988, p. 219) quando ele sustenta a ideia de que "uma construção perceptiva do mundo (...) como incessante atribuição 
de sentido (...) desemboca em uma fenomenologia da semiose"; "nessa perspectiva, a semiótica visa mais o estudo da constituição do significado que o do uso dos significados constituídos e codificados que a cultura nos propõe"; e ele acrescenta que levar em consideração "os clássicos da fenomenologia pode abrir o caminho a uma semiótica da mensagem [do discurso] mais rigorosa", mas também mais dinâmica, já que ela não levará somente em consideração "as convenções que regem o funcionamento dos signos, mas os processos mesmos da produção de signos e da reestruturação dos códigos" (ECO, 1988, p. 219). É esse caráter dinâmico da semiose discursiva que se encontra conceituado em Merleau-Ponty como "tradução" e em Benveniste como "reprodução": o discurso re-produz a realidade tanto para a instância de origem quanto para instância de recepção, e o "ser social", suporte do "pensamento" comunicável, traduz a experiência do "ser humano" em contato imediato e irrefletido com o mundo ao redor. Em outras palavras, a perspectiva fenomenológica engloba a perspectiva antropológica e o ganho de inteligibilidade é, desta maneira, certamente muito elevado.

Merleau-Ponty (1960, p. 149) já havia circunscrito o problema, ao indicar, do ponto de vista fenomenológico que era o dele, os limites da perspectiva objetivante da antropologia cultural, lembrando que se ela consegue destacar, a partir dos fenômenos culturais, "uma infraestrutura formal (...), um pensamento inconsciente, uma antecipação do espírito humano", não deve ser esquecido, no entanto, que "as surpreendentes operações lógicas que atesta a estrutura formal das sociedades" são "de alguma maneira realizadas pelas populações que vivem esses sistemas": deve portanto haver "uma espécie de equivalente vivido [dessas operações lógicas e formais], que o antropólogo tem que pesquisar".

Essas reflexões de Merleau-Ponty podem dar lugar a duas interpretações epistemológicas diferentes. A primeira, a mais comum, consiste em ver nelas a afirmação de que a antropologia cultural e as ciências do homem em geral operam uma redução da riqueza e da profusão dos dados fenomenológicos puros. Esta crítica não seria pertinente, uma vez que em toda disciplina com vocação científica, o "método" é inseparável do "objeto". Não podemos, por exemplo, censurar o botânico por ele colocar entre parênteses o aspecto estético das plantas que estuda (BENVENISTE, 1966; 1974, p. 117). A outra maneira de compreender a crítica de Merleau-Ponty é de aí ver um questionamento do valor das explicações avançadas pela antropologia cultural e a afirmação de que ela distorce seu objeto empírico criando um artefato. A crítica do filósofo, entendida desta maneira, constitui um convite a substituir um ponto de vista redutor por um outro mais respeitoso dos dados complexos da experiência. O antropólogo, segundo Merleau-Ponty, deve conformar seu pensamento à experiência que os membros da sociedade têm das estruturas inconscientes que regem suas condutas sociais. Em outras palavras, o pesquisador deve adotar a "perspectiva fenomenológica", única perspectiva que permite compreender a maneira como são vividas as estruturas inconscientes. 
Parece-nos que Greimas, em virtude do "princípio de pertinência", adotou sobretudo a primeira interpretação em resposta a várias críticas similares àquelas formuladas por Merleau-Ponty ${ }^{8}$ (GREIMAS; COURTÉS, 1979, p. 276). Coquet, ao contrário, se ateve à segunda e decididamente inscreveu sua prática analítica no âmbito da fenomenologia da linguagem. É nesse sentido que se deve entender porque ele descobre, nas análises de Greimas e Courtés $(1979,276)$, "uma espécie de isomorfismo entre o modelo [teórico] e o campo de aplicação sobre o qual ele se debruça", de tal maneira que "os textos [analisados] tomam por sua vez a forma previsível do objeto fechado" (COQUET, 1997, p. 223).

O traço distintivo da fenomenologia da linguagem é que ela faz sua a convicção (remontando à retórica aristotélica) que "há, por trás de todo ato de linguagem, um ser que fala e que está implicado neste ato". Pois "é sempre questão de si no dizer" (MEYER, 1991, pp. 51-52). O interesse dado a esse sujeito presente por trás do discurso já havia conduzido Coquet, em seus textos dos anos setenta, a questionar a posição que consiste em considerar que o único "ser" implicado pelo discurso é a "autoridade social", como se (é o tema do "simulacro" tão caro a Greimas) "a Sociedade se colocasse em cena sob a forma de arquétipos executando um programa muito estrito" - o que equivale, segundo Coquet (1974, p. 67), a escamotear o caráter específico de toda produção discursiva. É o que o conduz a defender abertamente uma limitação do "domínio de validade" da semiótica greimasiana àquilo que ele denomina "o espaço social" onde se produzem os "discursos sem Eu" - contos, mitos, provérbios e ditados, em suma, todas as práticas discursivas normalizadas (COQUET, 1997, p. 223) (GENINASCA, 1997)9 . Aí não se trata de um simples convite a se limitar ao estudo de um tipo determinado de discurso. Trata-se mais amplamente de fazer entender que a adoção de um princípio de pertinência decorrente da perspectiva antropológica aprisiona o semioticista na pesquisa do que cada discurso particular "deve" às coerções semióticas constitutivas do "espírito humano". Levar em consideração o "discurso com Eu" será, ao contrário, mudar de princípio de pertinência. Reconhecendo em todo discurso "a expressão de uma relação com o mundo" específica (Benveniste), isso conduzirá a adotar o ponto de vista fenomenológico e a defender o retorno ao sujeito que "enuncia sua realidade vivida" (COQUET, 2007, p. 21).

No início da empreitada crítica de Coquet, o levar em consideração do "Eu" se faz no quadro da concepção narrativa do discurso. Seu ponto de partida é a definição que Benveniste dá no que refere ao sujeito da enunciação: "é Ego quem diz ego". Esta definição, fechada em uma concepção oral e locutória, é especificada e generalizada por Coquet (1978, p. 2-4) da seguinte maneira: "é Ego quem diz ego e quem se diz Ego ou que é dito Ego". O "sujeito enunciante faz conhecer o tipo de participação no programa que instaura ou que ele assume", na medida em que ele é "aquele que é reconhecido,

8 O princípio de pertinência pode ser definido como "a regra deôntica que adota o semioticista, de descrever o objeto escolhido a partir de um único ponto de vista (...), retendo por conseguinte, para sua descrição, somente os aspetos a que interessa esse ponto de vista".

9 Posição prudente e positiva que nos parece de longe preferível àquela adotada por Jacques Geninasca que se reduz, no fim das contas, a jogar o bebê junto com a água do banho! 
seja por ele mesmo, seja pelos outros, como responsável da execução do programa" (COQUET, 1978, p. 2, 4). Temos nesse caso uma concepção "diatética" da enunciação que vem em linha direta de Benveniste e de sua caracterização do "campo posicional do sujeito", constituído das categorias da pessoa, do número (singular ou plural) e da voz (diátese). Para o analista trata-se, com efeito, de estatuir sobre "o grau de participação do sujeito no processo no qual ele está engajado" (COQUET, 1973, p. 80). Apresentada dessa maneira, a enunciação não é necessariamente associada ao uso da forma "eu" ou do "discurso direto". O "ele", tradicionalmente chamado "terceira-pessoa", e definido por Benveniste, nas célebres análises, como "não-pessoa", ou caracterizado como "ausência da pessoa", reenvia ele também a um ser identificável pela "capacidade de designar a si mesmo", propriedade que se encontra, como coloca Paul Ricœur (1980, p. 69), "transferida da primeira à terceira pessoa, à maneira de uma citação posta entre aspas. A outra, a terceira pessoa, diz em seu coração: 'eu afirmo que'".

A enunciação constitui dessa forma uma camada semântica suplementar que vem necessariamente se enxertar sobre o plano das estruturas semio-narrativas (actantes e programas) que lhe servem de suporte: o sujeito "se enuncia" através de seu fazer. "Se enunciar" quer dizer se fazer conhecer como dotado de uma certa identidade (ser qualquer coisa ou qualquer um) ou, em termos fenomenológicos, como a origem da "expressão de uma relação ao mundo". Em outras palavras, o "sujeito" como agente de um programa de ação está situado no mundo, mas ao "enunciar" sua identidade, ele se significa (ou é significado) como "ponto de perspectiva privilegiado sobre o mundo", ou ainda como "o limite do mundo" (RICOEUR, 1980, p. 67). Por exemplo quando, na Eneida, Virgílio descreve da seguinte maneira o comportamento de Vênus no episódio do encontro com seu filho Eneias (que não a reconhece): “... ao ela se afastar, uma luz, ao redor de sua nuca de rosas, resplendeu; (...) e, verdadeira deusa, por seu andar, como tal ela apareceu", ele mostra de fato a maneira pela qual a deusa se "dá a conhecer, ou, se quiser, (...) como ela 'enuncia' sua identidade" (COQUET, 2007, p. 77). O "sujeito" significa pelo seu agir ou seu dizer, porém, mais ainda, ele significa qualquer coisa de si mesmo, de sua identidade ou de sua relação com o mundo.

Esta enunciação "dialética" nos coloca em presença de uma semiose particular na qual o plano de expressão é constituído pelo fazer verbal e não verbal do actante e onde o plano do conteúdo é a própria identidade do agente desse fazer ou a sua relação com o mundo. Em termos hjelmslevianos, o plano do enunciado (o programa de ação) constitui o plano de denotação pela enunciação da identidade que é, desta maneira, um plano conotativo da semiose discursiva. Deve-se dizer também que esta concepção tão original nos parece ligada àquela que certos filósofos consideram como a propriedade fundamental da linguagem desde sua caracterização por Aristóteles: sua "interrogatividade" ontológica que o analista, enquanto instância de recepção do discurso, deve evidenciar (MEYER, 1991, p. 42). Mesmo na "linguagem assertórica" (numa narração, por exemplo), 
“a interrogatividade está presente, como um traço, uma origem, uma significação (...) já que na ausência da questão explícita à qual se responde, o público deve reconstruí-la, inferi-la, deduzi-la". Desta maneira, o "sujeito" discursivo não se contenta com dizer ou agir, mas, além disso, ele enuncia sua identidade em resposta à questão implícita na instância da recepção: quem ele é para dizer ou fazer aquilo que ele diz ou que ele faz? A análise do discurso, seguindo Coquet (1984, p. 25), tem por objeto "cernir a identidade dos actantes" discursivos ou, de maneira mais geral, responder a esta questão semiótica: "como, pela linguagem verbal ou não verbal, nós mesmos nos significamos?", questão esta que se apoia em um questionamento propriamente fenomenológico: "como, pela nossa posição no mundo, por nossa inserção em um campo de realidade (Sachfeld), por nossa presença, fazemos nós sentido, para nós e para outrem?" (COQUET, 2007, 175). A interrogação semiótica se articula sobre seu fundamento que é a questão fenomenológica e constrói, desta maneira, o objeto mesmo da fenomenologia da linguagem, a saber a ligação intrínseca, tecida no discurso, entre o "vivido" e o "sentido". Daí, defronte o princípio de imanência que permite cernir a "autonomia semântica" do discurso (RICOEUR, 1995, p. 120), um princípio de realidade que preconiza, sobretudo, não suspender a relação entre a "base" que é o "Lebenswelt" e sua chegada à linguagem (RICOEUR, 2000, p. 951).

Ao nosso conhecimento, o primeiro a ter tentado quebrar o interdito que pesa sobre esse gênero de questionamento e que tentou pensar, no quadro da linguística e da semiótica, a relação da linguagem com a realidade é Émile Benveniste (1966; 1974, p. 110-131, p. 43-66, p. 215-238). De fato, desde sua identificação dos "níveis de análise linguística" até as suas reflexões semiológicas sobre "A forma e o sentido", ele desenvolveu uma abordagem do discurso - considerado como o "por em ação" da linguagem — que dá conta de sua imersão no mundo-da-vida. Assim, quando ele circunscreve dois "modos de significação", (BENVENISTE, 1966; 1974, p. 51)10 o semiótico por um lado, o semântico por outro, ele os caracteriza cada um por um certo número de propriedades entre as quais emerge, para aquilo que nos interessa aqui, o fato de que, tratando-se do modo semiótico, o sentido é "intralinguístico" e "genérico", enquanto que, no domínio semântico, aquele do discurso, ele se encontra dotado de um "intentado" e de uma "referência" a um "estado de coisas" ou a uma "situação de discurso ou de fato". É claro que no modo semiótico, regido pelo "princípio de imanência", somente conta, do ponto de vista da instância de recepção, o "reconhecimento" desta ou daquela "unidade" como significante e não o que ela significa. O modo semântico, ao contrário, implica em um processo de "compreensão" que, para se realizar, deve conjugar o "intentado" da enunciação e a "referência" do enunciado. Nesse nível, é o princípio de realidade que guia a recepção.

10 A palavra "signifiance" em Benveniste remete simplesmente a "propriedade de significar", aquilo que permite distingui-la do termo "sentido". Não possui, portanto, as conotações psicanalíticas e quase esotéricas que assume em Kristeva ou Barthes, por exemplo. Nos parece, contudo, o equivalente moderno dos "modos de significar" dos medievais. 
A semiótica de Greimas (1976, p. 139) supõe, como tentamos mostrar anteriormente, que o analista visa antes de tudo a "reconhecer" no discurso e seu sujeito estruturas e coerções cuja instância produtora é o "espírito humano". Deste ponto de vista, o "sentido" só pode ser genérico e a análise consiste antes de tudo em identificar as invariantes imanentes independentes de qualquer "realidade sociológica ou psicológica" particular, tais como, por exemplo, as "estruturas axiológicas" conceituais ou figurativas que são supostas reger "as primeiras articulações dos universos semânticos". Mas, ao se basear sobre o imanente e o genérico, esquece-se de que, na atividade discursiva, como afirma Ricœur apoiado em Benveniste, "a linguagem faz referência ao sujeito falante, por meio de certos "indicadores" (eu, tu, ele), e que faz referência à realidade pelo jogo complexo do sujeito e do predicado". O discurso não é separado do Umwelt do qual seu produtor faz parte. O por em destaque o princípio de realidade também aparece como uma recomendação salutar endereçada aos analistas da linguagem. Com efeito, o rejeito dessa dupla referência (ao mundo e ao produtor) fora da "esfera linguística" corresponderia à "eliminação da própria função simbólica". De maneira geral, quanto mais a análise da linguagem "se esgota e se reduz à ciência", que somente pode, como vimos, visar o genérico e o universal, "mais ela expulsa de seu campo aquilo que diz respeito à relação da linguagem com qualquer realidade situada fora dela mesma" (RICOEUR, 2000, p. 937). Compreende-se porque, quando ele aborda o funcionamento do discurso no âmbito da "fenomenologia da linguagem" - que consiste, para ele, a sempre remeter o discurso à "experiência que precede a linguagem" -, Ricoeur (2000, pp. 950-953) considera que, "por uma semântica específica", o discurso "designa ele mesmo sua própria dependência àquilo que o torna possível do lado do mundo", a saber, pensamos, o que Coquet (1997, pp. 37, 39 e 114) denomina os "centros de discursividade" ou as "instâncias enunciativas". Dali a correção trazida à noção de discurso: esse é sempre, como para Greimas, um "todo significante" mas "reportado a uma ou mais instância(s) enunciativa(s)".

Em suma, tanto para Benveniste e Ricœur como para Coquet, a linguagem enquanto "discurso" e não enquanto "sistema" de significação, "é orientada para além de si mesma", e, em seu funcionamento, ela mostra que seu produtor "ambiciona trazer à linguagem e partilhar com outrem uma experiência nova". A objetividade do mundo e a intersubjetividade da comunicação são sempre implicadas pelo ato da linguagem e é necessário pôr em questão toda pretensão de reduzir a linguagem a um sistema autônomo de relações imanentes. Trata-se de proclamar, ao encontro do arbitrário radical de Saussure, que "a linguagem não constitui um mundo por ela mesma", e que se deve, antes, dar destaque à "pressuposição ontológica da referência, pressuposição refletida no interior da linguagem ela mesma como um postulado despido de justificativa imanente" (RICOEUR, 1983, p. 118). O princípio de realidade, tal como o formula Coquet, supõe que a realidade seja "uma grandeza integrada à linguagem" (BENVENISTE, 1978, 
p. 232) ${ }^{11}$. Desta maneira, a análise do discurso "não pode ser conduzida adequadamente a não ser que linguagem e realidade sejam consideradas como duas grandezas que se interpenetram" (COQUET, 1997, p. 243).

É nessa direção que se empenha explicitamente a pesquisa semiótica de Coquet ao tentar primeiro caracterizar, como vimos, a instância enunciante projetada no discurso enquanto "sujeito enunciador" ou "actante enunciador", e, em seguida, abordar o produtor do discurso (locutor ou escritor) e seu receptor (leitor, auditor ou analista) identificados respectivamente como "instância enunciadora de origem" e "instância de recepção", instâncias que precisam ser caracterizadas para além das restrições funcionais implicadas pela concepção imanentista da linguagem.

A introdução da instância de origem ao lado da instância projetada faz com que o discurso, sobretudo quando ele toma a forma de texto literário, se apresente como um dispositivo significante organizado em patamares. O primeiro patamar é ocupado pela instância de origem que não é mais que "a projeção do ser humano e do ser social" pois existe, respeitando o princípio de realidade, um contínuo entre o ser e a linguagem (COQUET, 2007, p. 74). A partir desse patamar, a primeira instância pode projetar-se sobre um segundo patamar. Esta instância projetada (uma personagem, por exemplo) pode tornarse, por sua vez, instância de origem que projeta um terceiro patamar, e assim por diante. Nenhuma ruptura ou "debreagem" é pensada entre a primeira instância e suas diferentes projeções, o que não é o caso no pensamento linguístico comum que não vê no "sujeito da enunciação", tido também "ego", que o "sujeito da frase declarativa subjacente a todo enunciado: 'eu te digo que'" (DUBOIS, 1973, p. 182). O produtor do discurso é então reduzido a uma simples instância funcional. Greimas (1979, p. 128), como mostramos, o concebe desta maneira. Quando ele fala do "enunciador", ele o considera de um ponto de vista funcional: é aquele que cumpre o papel de "destinador implícito da enunciação" ou de "pressuposto lógico do enunciado". No entanto, não se deve esquecer-se de que " $O$ homem que fala" não é senão uma projeção objetivante e funcional do "homem que fala".

Tomemos um exemplo para ilustrar essa divergência de pontos de vista. Seja a frase seguinte, extraída de um discurso de Marguerite Duras sobre uma de seus personagens: "Quando eu falo, sou Aurélia Steiner". Ao se seguir o pensamento comum, essa frase poderia ser reescrita como: "(Eu digo que) quando eu falo, ...", mas, procedendo desta maneira, o analista mudaria abusivamente os dados na medida em que estabeleceria uma distância objetivante entre Duras e seu discurso. Esse discurso nos convida a reviver, através de um processo de projeção subjectivante que implica em uma continuidade existencial entre a instância de origem e a instância projetada, uma experiência singular, aquela de identificação entre Duras, como locutor, e a personagem da qual ela fala. O que torna

11 Quando Julia Kristeva analisa, na linha de Benveniste, a "função predicativa" constitutiva do discurso, ela a considera como dotada de "uma função anafórica" que "asserta (...) um sujeito e um 'referente'. O sujeito enunciativo e o referente são coextensivos ao ato predicativo e não existem sem ele" ("La fonction prédicative et le sujet parlant".. 
possível esse processo de identificação imediata não é outro que o próprio corpo através da voz: "quando eu falo...". A instância corporal dá lugar à instância judicativa que afirma o fenômeno fugidio da identificação: "... eu sou...". Nessa frase, nós nos deparamos com dois patamares discursivos: o patamar da instância de origem sujeito que afirma e o patamar da instância projetada não-sujeito, aquele do corpo próprio que participa, sem o assumir, a um fenômeno de identificação entre dois corpos. Por isso, não se pode falar aqui de distância ou debreagem sem rejeitar os imperativos do princípio de realidade. Para serem tratados adequadamente, tais fenômenos discursivos requerem de maneira mais geral uma "semiótica do contínuo", na medida em que a passagem de um patamar de discurso a outro e, portanto, de uma instância à outra, se faz frequentemente de uma maneira insensível e não pode, por consequência, ser apreendida em termos lógicos de oposições e de diferenças, mas somente em termos topológicos de limiares e de transições (COQUET, 1978, p. 12).

Ao colocar a instância enunciadora como produtora do discurso e não somente como agente de um programa de ação, Coquet centra seu interesse sobre a instância de origem e passa de uma concepção "diatética" da enunciação a uma concepção "polifônica". De fato, pela escrita ou pela palavra, a instância de origem constitui o lugar de onde duas "vozes" se fazem entender e configuram cada uma um "universo de significação": as "vozes" complementares, mas distintas da physis e do logos. Sabemos, a noção de "polifonia" foi levada adiante por Oswald Ducrot (1984, p. 171-233) em seus trabalhos sobre a atividade da linguagem. Fiel ao princípio de imanência, ele descarta o "sujeito falante" como produtor efetivo do enunciado em benefício do "locutor" (produtor do ato ilocutório do qual faz estado o enunciado) e do "enunciador" (origem de "um ponto de vista", de uma "opinião", mais precisamente, de uma proposição constitutiva do enunciado). Por sua vez, Coquet (2007, p. 8) considera que o "sujeito falante" ou o "sujeito escritor" não devem estar situados fora das preocupações do analista do discurso, dado que o respeito do princípio de realidade leva a aí ver o "referente", o "aquém" ou ainda o "correlato objetivo" da produção do discurso. Assim, nessa ordem de ideias, falar-se-á de uma instância de origem, fonte última ${ }^{12}$ do discurso, que ora faz entender a única voz do logos, fazendo "silenciar" aquela da physis, ora ao contrário a deixa entender também, por intermitência. A voz da physis se manifesta discursivamente naquilo que Coquet (2007, p. 8) denomina "predicados somáticos", a respeito da instância corporal, em relação ou não com uma força imanente que a domina, pois eles "notam a percepção, a duração de um fenômeno, sua aparição ou desaparição, ou o contato, em particular a posição no espaço, a proximidade ou a distância, ou o grau de um afeto, etc.". O logos se faz ouvir nos "predicados cognitivos" que, todos, remetem à atividade de "julgamento" característica da instância sujeito e de sua projeção no universo da heteronomia, o terceiro

12 Último, pois o analista não pode ir além sem sair do campo semiótico detendo-se em considerações de ordem biográfica, psicológica ou sociológica 
transcendente. $\mathrm{O}$ "julgamento" pode tomar diferentes formas, mas todas remetem à duas operações fundantes: a "asserção" e a "assunção" (COQUET, 2007, p. 23).

Ademais, embora mantendo um vínculo de projeção objetivante ou subjetivante com seu discurso, a identidade da instância de origem pode ser semioticamente instável, heterogênea e multidimensional. Essa abre espaço a uma combinatória flexível e maleável que permite tanto de acompanhar de muito perto um devir contínuo do discurso quanto de proceder a uma tipologia extremamente fina das diferentes instâncias enunciantes (COQUET, 2007, p. 65).

Enquanto instância de recepção, o analista do discurso é convidado, por sua vez, ao respeito do princípio de realidade caso deseje que sua análise não force os dados até a construção de artefatos. Observando que o analista é "constrangido às mesmas coerções que os actantes do discurso, ainda que não diga ou não saiba, geralmente, nada", Coquet (1978, p. 206) foi um dos primeiros a se interrogar sobre seu estatuto (COQUET, 1984, p. 206; LANDOWSKI, 2004, p. 26-32 $)^{13}$. Ele se coloca a propósito uma questão urgente recorrendo aos termos aforísticos de Nietszche: "Pode ele dançar?". Em outras palavras, será que ele se concebe como um participante da "dança" à sua frente? ou que ele se restringe a um papel de observador neutro, instaurando uma distância objetivante entre ele e a "dança" observada? Sabe ele ou não que a objetificação excessiva é mutilante porque conduz, "irreversivelmente, à rejeição da experiência sensível para reter apenas a experiência do pensamento" (COQUET, 1978, p. 12)?

Tomemos um exemplo para ilustrar essas proposições talvez demasiadamente gerais. Veja esse fragmento tirado do famoso episódio da Madeleine em No caminho de Swann de Marcel Proust:

Fazia já muitos anos que, de Combray, tudo que não fosse o teatro e o drama do meu deitar não existia mais para mim, quando num dia de inverno, chegando eu em casa, minha mãe, vendo-me com frio, propôs que tomasse, contra meus hábitos, um pouco de chá. A princípio recusei e, nem sei bem por que, acabei aceitando. Ela então mandou buscar um desses biscoitos curtos e rechonchudos chamados Madeleines (...) E logo, maquinalmente, acabrunhado pelo dia tristonho e a perspectiva de um dia seguinte igualmente sombrio, levei à boca uma colherada de chá onde deixara amolecer um pedaço da Madeleine. Mas no mesmo instante em que esse gole, misturado com os farelos do biscoito, tocou meu paladar, estremeci, atento ao que se passava de extraordinário em mim. Invadirame um prazer delicioso, isolado, sem a noção de sua causa. Rapidamente se me tornaram indiferentes as vicissitudes da minha vida, inofensivos os seus desastres, ilusória a sua brevidade, da mesma forma como opera o amor, enchendo-me

13 Com lucidez, Landowski interroga também o estatuto do analista das práticas significantes. Ele distingue a esse propósito duas atitudes inconciliáveis: a "apropriação", que trata "o outro" (enquanto objeto de análise) "como um objeto" e a "realização" ("accomplissement"), que o considera "como sujeito". A escolha da segunda opção mostra que "a construção do sentido não pode ser concebida semioticamente de outro modo que como um processo que engaja, que compromete, que implica o sujeito na sua relação com o outro (qualquer que seja a forma em que se apresente)". 
de uma essência preciosa; ou antes, essa essência não estava em mim, ela era eu. Já não me sentia medíocre, contingente, mortal. De onde poderia ter vindo essa alegria poderosa? (...) De onde vinha? Que significaria? Onde apreendê-la?

Um analista que se concebe como um observador neutro, no limite um "autômato", procurará nesse texto aquilo que se "deve" às coerções semióticas transindividuais e, portanto, objetiváveis (GREIMAS; COURTÉS, 1979, p. 323) ${ }^{14}$. O texto aparecerá assim como uma variável (GREIMAS, 1976, p. 263) ${ }^{15}$, uma realização particular do esquema geral da "inversão dos signos do conteúdo" (GREIMAS, 1970, p. 187). De fato, a organização semântica transfrásica do texto faz passar de um conteúdo invertido ("oprimido pela morna jornada e a perspectiva de um triste amanhã") a um conteúdo posto ("eu havia deixado de me sentir medíocre, contingente, mortal"), de um estado caracterizado pela disforia a um estado eufórico. O analista-observador constatará também que os estados de alma do protagonista (que correspondem aos "valores descritivos" com os quais ele se encontra "conjunto" ao ponto de partida e ao ponto de chegada do "algoritmo narrativo") constituem o "referente interno" da "dimensão cognitiva" que se desenrola no discurso sob a forma de interrogações que o narrador-participante se endereça a si mesmo. Pode-se ainda refinar a análise na tentativa de se identificar, por exemplo, a "competência modal" que torna possível a transformação patêmica.

Esta análise objetivante reduz o texto de Proust ao estatuto de uma realização particular dos esquemas e algoritmos universais aos quais os mitos e os contos obedecem (BARTHES, 1970, p. 9) ${ }^{16}$. Não se considera aquilo que é específico ao texto, mas o que o pode aparentar a outros objetos que aparecem ao mesmo tempo como semelhantes e diferentes. Na linguística ou na semiótica, o fazer científico implica a obrigação de não levar em consideração, no conjunto de dados estudados, mais que suas "características comuns" (COURTÉS, 1976, p. 34). Pelo contrário, se o analista assume o princípio de realidade, ele será mais sensível ao caráter singular e estranho da experiência colocada pelo texto de Proust. Para tal, deve-se levar em consideração o "intentado" do escritor, a saber, como coloca Benveniste, a "atualização linguística de seu pensamento", ou nos termos de Coquet (2007, pp. 75, 77), a "tradução" ou a "re-produção" da experiência corporal nos predicados discursivos (BENVENISTE, 1966, 1974, p. 225; COQUET,

14 Uma das condições da cientificidade, afirmam Greimas e Courtés, "consiste em dar ao discurso científico uma forma tal que o sujeito científico (...) possa funcionar como um sujeito qualquer (...) susceptível, no limite, a ser substituído por um autômata".

15 A "maneira de ler" que o semioticista deve adotar, escreve Greimas, "consiste, a cada vez que se encontra em presença de um fenômeno não analisado, construir sua representação de tal maneira que o modelo seja mais geral que o fato examinado o exige, a fim de que o fenômeno observado se inscreva como uma de suas variáveis".

16 Barthes faz uma observação análoga a respeito das "primeiras análises do relato". 
2007, pp. 75, 77); GENETTE, 1995, p. 100, 1983, pp. 68-69) ${ }^{17}$. Com efeito, o narradorprotagonista, enquanto instância de origem, instala em seu discurso um processo de projeção subjetivante desde o momento em que se trata para ele de traduzir nas formas linguísticas não um acontecimento delimitável e objetivável mas uma experiência singular, uma espécie de epifania da qual ele foi a sede[17]. Assim, a instância judicativa, o sujeito que julga negativamente sua existência sobre o modo da disforia, vai bruscamente ceder seu lugar de centro discursivo a uma instância corporal, a um não-sujeito ligado à experiência que o faz advir: "no mesmo instante em que esse gole, misturado com os farelos do biscoito, tocou meu paladar, estremeci, atento ao que se passava de extraordinário em mim". Essa transformação instancial se faz sobre o modo do imediato temporal e da proximidade espacial ("toca meu paladar"), que constituem os traços característicos da instância corporal deixando ouvir a voz da physis. O termo "atento" constitui um predicado cognitivo que marca o retorno ao regime do julgamento e à instância sujeito que vai, aliás, avaliar positivamente, como eufórico, seu estado de alma final. Se o patêmico se exprime na instância sujeito no modo da euforia ou da disforia, a paixão manifesta-se em termos de satisfação incontrolável e imprevisível na instância corporal: "Invadira-me um prazer delicioso, isolado, sem a noção de sua causa". Para determinar essa força imanente que "invadiu" o corpo e tornar comunicável sua identidade, a instância judicativa não encontra outro meio que a assemelhar com um terceiro transcendente reconhecido socialmente: "o amor".

Esse tipo de análise põe ênfase tanto sobre a instabilidade do estatuto das instâncias enunciantes quanto sobre o enraizamento do sentido na realidade do mundo sensível: o ponto de partida das interrogações (logos) do protagonista não é outro que o contato imediato e irrefletido do corpo com o mundo (physis). Enquanto instância primeira deste texto, Proust assume o princípio de realidade, o que não quer dizer que a instância de recepção o fará igualmente. Vimos que uma leitura imanentista do texto é perfeitamente realizável. Na matéria, o critério deve sempre ser o "ganho de inteligibilidade" e o respeito dos dados textuais como, do resto, nos lembrava com força o fundador da semiótica estrutural: "o texto não é senão o ponto de partida e o ponto de ancoragem de nossas vociferações, se assim se pode dizer, é ele que as justifica e as funda (GREIMAS, 1987, p. 302)".

Como antídoto eficaz contra o sectarismo e a intolerância intelectuais, Coquet recomenda frequentemente recorrer à história das ciências e das ideias. No presente caso, esse recurso nos permite detectar no estudo da linguagem, desde o século XIX, uma oposição epistemológica entre aquilo que Bakhtine chama "objetivismo abstrato"

17 Não se trata aqui de regressar à "intenção" do autor, tão importante na abordagem filológica dos textos literarios, mas de considerar a presença incontornável do escritor como instância enunciante de origem. Sobre o assunto, Génard Genette, com muito bom senso, faz as seguintes observações: "Que o estatuto intencional das obras exista me parece uma certeza absoluta. Que a intenção do autor deve comandar a todo custo a interpretação das obras, é uma outra questão. A atenção dos receptores é livre em relação a intenção do autor, mas o que rechaço, é essa espécie de caricatura do pensamento estruturalista que outrora conhecemos, e que consistia em simplesmente negar o fato da intenção do autor".. Genette já havia criticado as narratologias que defendiam a ideia imanentista de que "ninguém fala na narrativa" afirmando com força que, para ele, "a narrativa sem narrador" ou "o enunciado sem enunciação" são "quimeras puras". E acrescentava, com humor: "quando eu abro um livro, é a fim que o autor me fale. E como ainda não sou surdo ou mudo, me ocorre de respondê-lo". 
e "subjetivismo idealista" (BAKHTINE, 1977, p. 74; COQUET, 1997, p. 147-148)18. Enquanto a adoção da visada antropológica e do princípio de imanência que ela implica se liga à primeira atitude, o avanço do tema da "enunciação" inscreve a concepção fenomenológica das instâncias enunciantes no âmbito da segunda. Essa oposição remonta, segundo Bakhtine, a Humboldt e à distinção que ele formula, em matéria de linguagem, entre energia e ergon, o que lhe permite focalizar sua atenção sobre a língua como discurso (Sprache als Rede). A mesma tomada de posição se encontra em Coquet através de Benveniste (1966, 1974, p. 131), pois, já nos anos sessenta, em pleno apogeu desse "objetivismo abstrato" que foi o estruturalismo formalista, ele havia sublinhado a primazia da atividade de linguagem (energeia) que é o discurso sobre o sistema da língua (ergon). "Nihil est in lingua quod non prius fuerit in oratione".

Enquanto fundador de um "projeto científico", Greimas queria consolidar a semiótica discursiva como "ciência", e por isso era preciso, de seu ponto de vista, descobrir e identificar "invariantes universais (LÉVI-STRAUS, 1971, p. 56)"19. Nesse sentido, ele tendia, como todo "sábio", a inserir seu pensamento no regime da apoditicidade. De onde sua insistência constante sobre os "esquemas", os "percursos" predeterminados (actanciais, narrativos, ...) e as "coerções semióticas" (CHEVALIER; ENCREVÉ, p. 237)²0. A ênfase na invariante em relação à variação desconcertante das coisas é um traço pertinente que, para os "sábios", separa o conhecimento positivo da especulação filosófica ou estética.

Colocado à parte esse excesso na redução científica, deve-se saudar como exemplares a vontade de rigor e exigência teórica características do pensamento de Greimas pois elas permitiram a correntes e tendências diversas de eclodir ao seu redor ou, até mesmo, contra ela, fazendo assim do "campo semiótico" o lugar da renovação do saber sobre a linguagem e a significação, e além disso, sobre o homem de maneira geral. Falar, como o fazem alguns, de "ultrapassagem" é, portanto, falar em vão: na verdade, trata-se, antes, do deslocamento dos centros de interesse. Como afirmava Lévi-Strauss (1973, p. 173) a respeito do trabalho desse outro pioneiro que foi Vladimir Propp, a obra semiótica de Algirdas J. Greimas "guardará o mérito perene de ter sido a primeira".

Traduzido do francês por Ana Claudia de Oliveira e Eric Landowski.

18 Sob a pena de Bakhtine, essas denominações não possuem nenhuma nuance pejorativa. Elas servem simplesmente, como ele mesmo indica, a çrcunscrever a grosso modo as tomadas de posição em relação com a atividade de linguagem. Coquet estabelece uma oposição paralela mas independente entre uma opção "sistêmica e estática" e uma opção "histórica e dinâmica".

19 Para Lévi-Strauss, "a descoberta de uma grande relação invariante" constitui "aquilo a que uma pesquisa que se quer científica deve aspirar" e o único "título de glória" ao qual ela deve aspirar.

20 Nicolas Ruwet conta em uma entrevista dos anos 80 como Greimas, em seu seminário de 1964, no instituto Henri-Poincaré, queria a todo custo fazer "um esquema da fuga", enquanto, segundo ele, musicólogo de formação, "não haja duas fugas em Bach que tenham o mesmo esquema". 
Ahmed Kharbouch é professor e pesquisador no Centre Universitaire des Langues et Communication da Universidade Mohamed Premier, Oujda, Marrocos. Especialista da semiótica literária. Tese de doutorado em Paris sob a direção de Jean-Claude Coquet. Escreve regularmente na revista Actes Sémiotiques. Entre outros publicou Des hommes et des femmes représentations sociolectales et structures sémiotiques dans les contes des "Mille et une nuits".

ahmed1962kharbouch@yahoo.fr

\section{Referências}

ARRIVÉ, M.; GADET, F.; GALMICHE, M. La grammaire d'aujourd'hui. Paris: Flammarion, 1986.

BAKHTINE, M. Le marxisme et la philosophie du langage. Paris: Minuit, 1977 (1929).

BARTHES, R. Mythologies. Paris: Seuil, 1957.

S/Z, Paris, Seuil, 1970.

BENVENISTE, E. Problèmes de linguistique générale. I et II. Paris: Gallimard, 1966 e 1974.

BOUQUET S.; ENGLER, R. (Orgs.). Ecrits de linguistique générale. Paris: Gallimard, 2002.

BRÉMOND, C. Logique du récit. Paris: Seuil, 1973.

CHEVALIER, J.-C.; ENCREVÉ, P. Combats pour la linguistique de Martinet à Kristeva. Paris: ENS éditions, 2006.

COQUET, J.-C. La relation sémantique sujet-objet. Langages, 31, 1973.

. Les modalités du discours. Langages, 43, 1974.

. Le discours et son sujet. Développement d'une sémiotique modale. (Entretien), Bulletin du groupe de recherches sémiolinguistiques. I, 1-2, 1978.

. L'Ecole de Paris. In: COQUET, J.C. (Ed.). Sémiotique. L'Ecole de Paris. Paris: Hachette,1982. L'implicite de l'énonciation. Langages, 70, 1982.

. Le discours et son sujet. Essai de grammaire modale. Paris: Klincksieck, 1984.

Préface. In: ARRIVÉ, M. Linguistique et psychanalyse. Paris: Klincksieck, 1986.

La quête du sens. Le langage en question. Paris: PUF, 1997.

Physis et logos. Une phénoménologie du langage. Paris: PUV, 2007.

COURTÉS, J. Introduction à la sémiotique narrative et discursive. Paris: Hachette, 1976.

CULIOLI, A.; NORMAND, C. Onze rencontres sur le langage et les langues. Paris: Ophrys, 2005.

DUBOIS, J. et al. Dictionnaire de linguistique. Paris: Larousse, 1973.

DUCROT, O. Le dire et le dit. Paris: Minuit, 1984. 
Logique, structure, énonciation. Paris: Minuit, 1989.

ECO, U. Le signe. Bruxelles: Labor, 1988.

. Sémiotique et philosophie du langage. Paris: PUF, 1988.

GENETTE, G. Nouveau discours du récit. Paris: Seuil, 1983. Entretien. Magazine littéraire. 328, 1995.

GENINASCA, J. Et maintenant? In: LANDOWSKI, E. (Org.). Lire Greimas. Limoges: PULIM, 1997. GREIMAS, A. J. L'actualité du saussurisme. Le français moderne, 3, 1956. . Sémantique structurale. Paris: Larousse, 1966.

Du Sens. Paris: Seuil, 1970. Sémiotique et sciences sociales. Paris: Seuil, 1976.

. Maupassant. La sémiotique du texte. Paris: Seuil, 1976.

1976. Entretien. In: NEF, F. et al. Structures élémentaires de la signification. Bruxelles, Complexe, .La sémiotique. In: La linguistique. Paris: Larousse, 1977.

Du Sens II. Paris: Seuil, 1982.

GREIMAS, A. J. Mis à la question. In: AAVV. Sémiotique en jeu. Paris-Amsterdam: HadèsBenjamins, 1987.

De I'Imperfection. Paris: Fanlac, 1987.

GREIMAS, A. J.; COURTÉS, J. Sémiotique. Dictionnaire raisonné de la théorie du langage. Paris: Hachette, 1979.

GREIMAS, A. J.; LANDOWSKI, E. Introduction à I'analyse du discours en sciences sociales. Paris: Hachette, 1979.

GREIMAS, A. J.; FONTANILLE, J. Sémiotique des passions. Paris: Seuil, 1991.

KRISTEVA, J. La fonction prédicative et le sujet parlant. In: AAVV, Langue, discours, société. Pour Émile Benveniste. Paris: Seuil, 1978.

LANDOWSKI, E. Passions sans nom. Paris: PUF, 2004.

LÉVI-STRAUSS, C. La pensée sauvage. Paris: Plon, 1962. Ramener la pensée à la vie. Entretien. Magazine littéraire, 1971. Anthropologie structurale deux. Paris: Plon, 1973.

De près et de loin (com D. Eribon). Paris: Odile Jacob, 1988.

MERLEAU-PONTY, M. Signes. Paris: Gallimard, 1960.

MEYER, M. Introduction. La rhétorique. Paris: LGF, 1991.

PEIRCE, C. S. Ecrits sur le signe. Paris: Seuil, 1978.

PETITOT, J. Les deux indicibles ou la sémiotique face à l'imaginaire comme chair. In: PARRET, H.; RUPRECHT, H.-G. (Orgs.). Exigences et perspectives de la sémiotique. Amsterdam: Benjamins, 1985. 
RICCEUR, P. Temps et récit. I. Paris: Seuil, 1983.

Soi-même comme un autre. Paris: Seuil, 1990.

La critique et la conviction. Paris: Hachette, 1995.

Philosophies du langage. In: Dictionnaire de la philosophie. Paris: Albin Michel/Encyclopaedia Universalis, 2000.

RUPRECHT, H.-G.; GREIMAS, A. J. Entretien. Ouvertures méta-sémiotiques. RSSI, 1, 1984.

SAUSSURE, F. de. Cours de linguistique générale. Paris: Payot, 1980 (1916).

ULLMANN, S. Précis de sémantique française. Berne: Francke, 1952.

Texto recebido em 15/07/2019

e aprovado em 20/10/2019. 